\title{
Proceeding
}

Supplementary Issue: Autumn Conferences of Sports Science. Costa Blanca Sports Science Events, 18-19 December 2020. Alicante, Spain.

\section{Rehabilitation of the wrist joint injury accordance of kinesiology variables}

\author{
NABEEL ABDULKADHIM ATHAB ${ }^{1}$, HAYTHEM ALI ALSAYIGH² \\ ${ }^{1}$ The College of Physical Education \& Sport Sciences, University of Babylon, Iraq \\ ${ }^{2}$ The College of Medicine, University of Babylon, Iraq
}

\begin{abstract}
This research aims to rehabilitate the wrist joint injury accordance of the variables of kinesiology, that the construction of rehabilitation exercises using kinetic aspect of wrist has a significant impact on determining the amount of the damage in the injured part, as identify the amount of force and increase it in the muscles operating under kinesiology movement. The researchers postulated that the use of kinesiology in a rehabilitation of a wrist joint, its active effect to increase muscle activity and strength and thus rework the activation of joint as a normally. Included research sample (6) of injured players in the wrist joint, specifically in the soft tissue, reaching the arithmetic mean age (21.68) and standard deviation (1.13), while the mean of height $(180 \mathrm{~cm})$ and standard deviation (2.1). After obtaining the data has been incorporated in the statistical software (SPSS) and results were presented in a special table prepared for it, and through the above researchers concluded: 1). A program of kinesiology positive effect in rehabilitation of the wrist joint speed up the healing process. 2). To the smart programs used in kinetic analysis of an active role in the calculation of the amount of force and variables of subsidiaries kinesiology. 3). The use of science kinesiology in rehabilitation programs with a significant impact in increasing muscular balance and stability hinge.
\end{abstract}

Keywords: Rehabilitation; Wrist joint; Injury; Kinesiology.

\section{Cite this article as:}

Athab, N.A., \& Alsayigh, H.A. (2021). Rehabilitation of the wrist joint injury accordance of kinesiology variables. Journal of Human Sport and Exercise, 16(2proc), S532-S538. doi:https://doi.org/10.14198//hse.2021.16.Proc2.37

Corresponding author. The College of Physical Education \& Sport Sciences, University of Babylon, Iraq.

E-mail: behnoush.hamdel@gmail.com

Abstract submitted to: Autumn Conferences of Sports Science. Costa Blanca Sports Science Events, 18-19 December 2020. Alicante, Spain.

JOURNAL OF HUMAN SPORT \& EXERCISE ISSN 1988-5202

(c) Faculty of Education. University of Alicante

doi:10.14198/jhse.2021.16.Proc2.37

S532 | 2021| Proc2 | VOLUME 16

C 2021 University of Alicante 


\section{INTRODUCTION}

The Applied Science has become today overlapping with each other whether it is in the medical field and sports or field of Computer Science, and we find it clear at various levels, as is now the computer science key for each lock through which can find solutions and simplify complex problems to be much easier and practical.

In this sense, I find that computer programs participated today and significantly to the development level of athletic performance for different games and contributed to provide different solutions to help get advanced results, and look Analytical wrist joint, we find it of great significance in most games sporting events that require the use of wrist joint in achieving best sports results and note Undoubtedly the number of injuries in athletes is increasing day after day and detailed wrist injury is one of those injuries that may lead to the player type practiced by the sporting event (McLean et al., 2007). That the incidence of, and on the face of the challenge detailed wrist injury occurs due to the use of modern technologies by coach through which could determine the level of the player and his health and on an ongoing basis to ensure maintaining the performance of the player and get to the top-level sports.

In light of the foregoing researcher used a program designed according to the programming languages smart to calculate the amount of the difference between the effectiveness of wrist joint injured when a sample of players before and after undergoing the program qualifying and therapeutic, because the benefit of this research is to determine the level of physical activity and range of motion of the joint, which is supposed to be upon the player the possibility of return to play and practice efficiency or sports game that is unique to the player.

Therefore, the use of computer programs is an important part in assessing the effectiveness of performance according to various parts of the body especially the wrist joint, which is the subject of research for its importance in directing the movements of various sports which require the participation of the upper limb in performance.

\section{Movements of the wrist (Hill \& Basic Biomechanics, 2012)}

The movements in the wrist joint are capable of sagittal and frontal plane movements, so the rotary motion (Figure 1). The motion of flexion in the palmar surface of the hand toward the anterior forearm .While the motion of extension in the return of the hand to anatomical position, and in hyperextension, the dorsal surface of the hand approaches the posterior forearm.
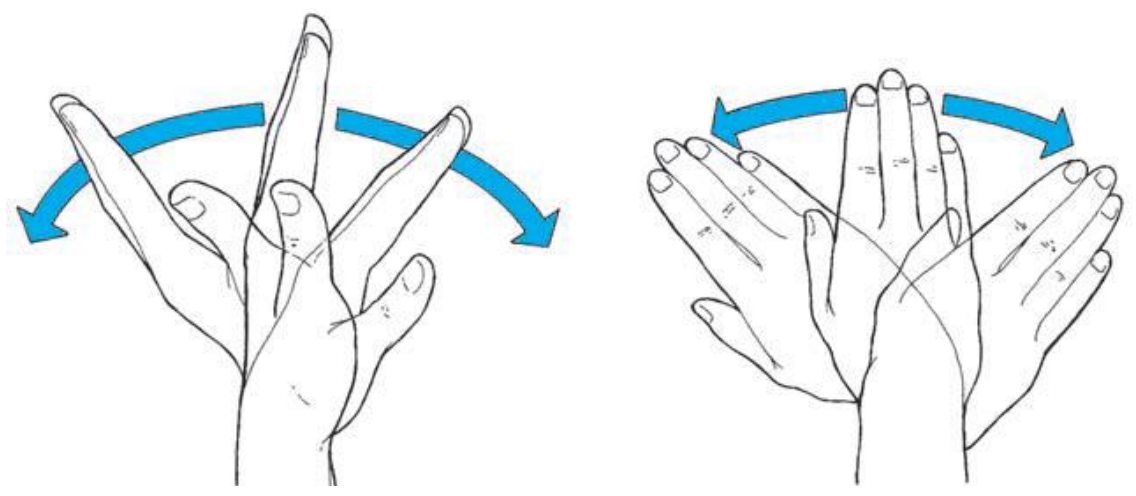

Figure 1. Movements occurring at the wrist (Floyd, 2004). 
Hand movements toward the thumb side of the arm is radial deviation, with movement in the opposite direction designated as ulnar deviation. Movement of the hand through all four directions produces circumduction. Because of the complex structure of the wrist, rotational movements at the wrist are also complex, with different axes of rotation and different mechanisms through which wrist motions occur.

\section{The effectiveness analysis of wrist joint according to the smart programs}

Analysis through experimentation works and leads us to come up with precise and accurate in detecting whether concomitant change in the movement to reach conclusions concerning the accomplishment, where they are invoked to describe the movement and analysis of all factors (physical, mechanical, anatomical) investigating motor performance so as to ensure their use in solving problems which relate to performance and evaluation through the balancing of these facts analytical certain criteria make it easier for coaches to choose the right exercises for the athletics motor performance and create the correct circumstances special training to achieve that goal (Hambangmoe-ro \& Sujeong-gu, 2015). The analysis using software Smart (PC) is of great significance in determining the nature perform each part of the body, especially wrist joint, as can these programs identify axes equitable parts of the body as well as find a range of motion for each part or as detailed, as through analysis software smart can calculate the power body or detailed as well as the speed of each part of the body to determine whether there was a disturbance or weakness in the body part on performance (Ben Aabdallah et al., 2016).

\section{METHODOLOGY}

\section{Subjects}

Included a sample search for injured players chronic pain in the wrist joint, as the number of members of the research sample (6) of injured players. It was conducted of homogeneity to the sample of search in the variables are length, age and training age, as shown in Table 1 :

Table 1. Analysed variables.

\begin{tabular}{lcccc}
\hline Variables & Mean & Std. Ev & Mode & Skewness \\
\hline Length & 180 & 2.1 & 178 & $0.00^{*}$ \\
Age & 21.68 & 1.24 & 20 & $-0.66^{*}$ \\
Training age & 7.82 & 0.749 & 7 & $0.44^{*}$ \\
\hline
\end{tabular}

Note: * The sample of research is homogeneity in the length, age and training age, and the cause the skewness value determined between ( \pm 3$)$.

\section{Task}

In order to keep the normal range of movement in the joint player injured and in order to protect players from risk screening random, were used computer programs smart to measure mechanical variables and physical before and after the subject individuals sample therapeutic program qualifying was confirmed that tests carried out on a sample search to not lead to side effects. As it was filmed the wrist of the player's hand movement in the case of flexion, extension ,hyperextension and deviation in maximum movement and analysis through intelligent analysis software, as grip strength was calculated by measuring device is intended for this test and connected to the (PC).

\section{Data collection}

Data were collected through Form prepared for this purpose, since data were obtained research variables studied by analysing the performance of injured players in the test on the movement of the wrist and 
previously mentioned and shown in Figure 2, add data power grip, which was obtained directly from the PC.So the measure of force endurance is calculating from this equation:

Force endurance $=$ Force $\times$ Time

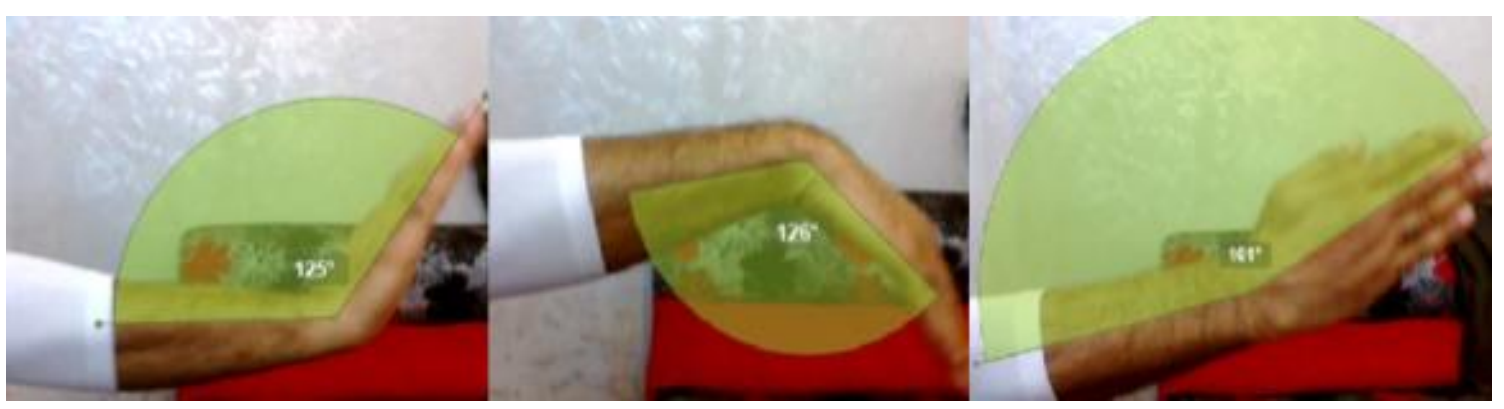

Figure 2. Show the measurements of motion range.

\section{Data analysis}

To study the differences between the results of the pre- and post-tests to sample of research with the work of the researchers to compare the results of both tests pre and post, after undergoing the sample search Qualifying therapeutic, to recognize through it to the amount of the real contribution of the program qualifying in the development of muscle activity working on the wrist joint as well as the amount of the differences in the strength and extent of detailed kinetic. This seems clearly differences in the number of developments in the results of pre and post-tests, which shows the effectiveness of the qualifying program to increase the effectiveness of detailed work and rehabilitation of the wrist.

\section{Statistical analysis}

The researcher used $(t)$ test of the samples corresponding to calculate the amount of the differences between the tests pre- and post-to the members of study sample, and through statistical program (SPSS) were data processing and tabulation in the tables to determine the value of $(t)$ at $(.05)$ level and the degree of freedom (5).

\section{RESULT}

The range of motion in the wrist joint

Table 2. Show the mean, Std. Ev and (t) test to range of motion in the wrist joint.

\begin{tabular}{lcccccc}
\hline \multirow{2}{*}{ Variables } & \multicolumn{2}{c}{ Mean } & \multicolumn{2}{c}{ Std. Ev } & \multirow{2}{*}{$(\mathbf{t})$ value } & \multirow{2}{*}{ Sig } \\
\cline { 2 - 5 } & Pre & Post & Pre & Post & & \\
\hline Flexion & 123.08 & 106 & 2.15 & 4.15 & 8.71 & .0 \\
Hyper EX. & 145.33 & 121.75 & 3.44 & 3.03 & 21.77 & .0 \\
Radial Deviation & 159.3 & 149.5 & 2.25 & 1.76 & 9.13 & .0 \\
Ulnar Deviation & 162.17 & 147.8 & 1.39 & 4.71 & 8.31 & .0 \\
\hline
\end{tabular}

The Table 2 refers to the existence of significant differences between pre and post-tests in the range of motion variables of wrist joint, because the value of ( $p$-value) is greater than the value of moral significance at the level of Sig. (.05). 


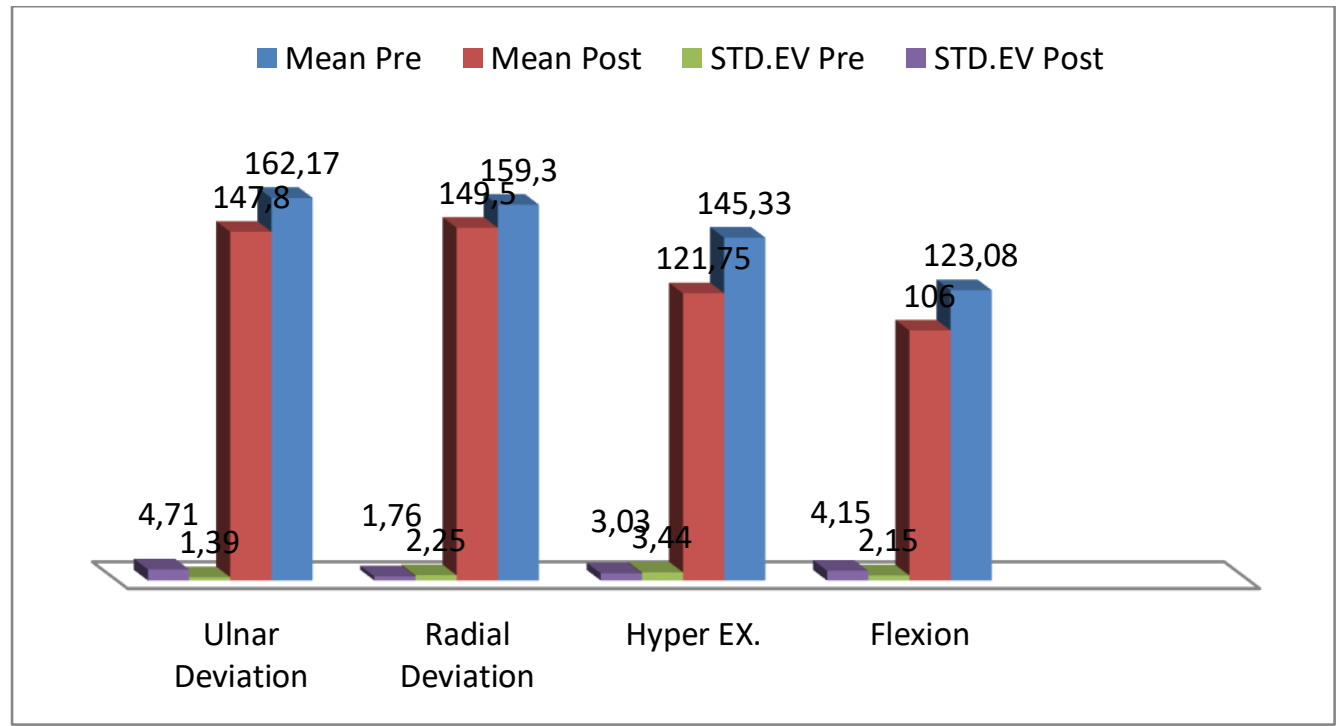

Figure 3. Show the mean and Std. Ev for the variables of ROM.

\section{Force of wrist joint}

Table 3. Show the mean, Std. Ev and (t) test to the force of wrist joint.

\begin{tabular}{lcccccc}
\hline \multirow{2}{*}{ Variables } & \multicolumn{2}{c}{ Mean } & \multicolumn{2}{c}{ Std. Ev } & \multirow{2}{*}{ (t) value } & \multirow{2}{*}{ Sig } \\
\cline { 2 - 5 } & Pre & Post & Pre & Post & & .09 \\
Grip force & 15.35 & 31.197 & 11.87 & 3.89 & 10.99 & .0 \\
Force Time & 0.09 & 0.26 & 0.008 & 0.49 & 7.2 & .01 \\
Force endurance & 1.43 & 8.16 & 1.65 & 2.24 & 7.07 & .01 \\
\hline
\end{tabular}

Through of the Table 3 ,we find are significant differences between the variables of hand grip force .and the cause is that ( $p$-value) is the biggest from the Sig value.

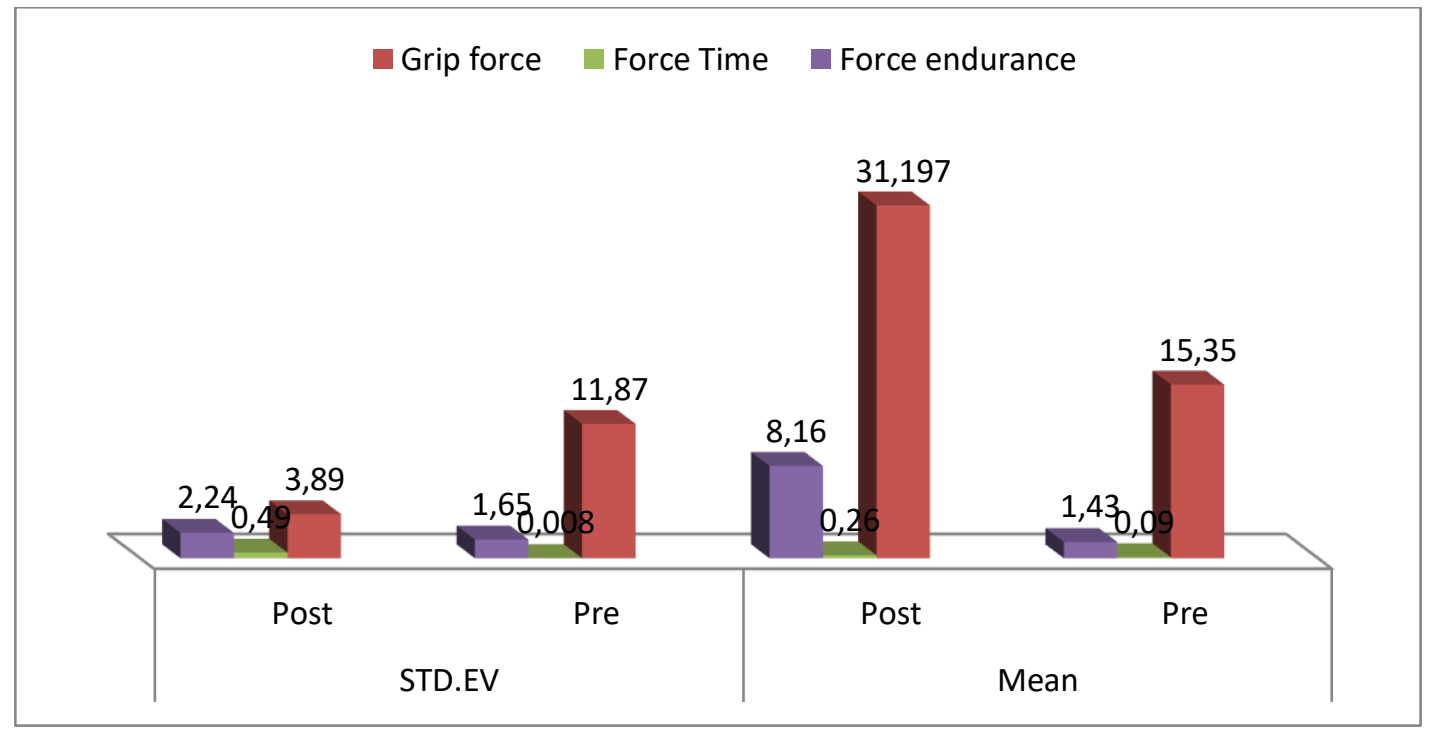

Figure 4. Show the mean and STD.EV for the variables of wrist joint force. 


\section{DISCUSSION}

Through what has been presented from the results in Table (2) and (3) shows that there are significant differences between the results of the pre-test and post-test, and this is pointed out to him the test ( $t$ ) and the value of moral significance. Program that rehabilitative prepared and who underwent a sample of the research contributed to the treatment the rehabilitation of the wrist joint by improving range of motion, and as shown in the results (Table 2).

Attribute the researcher of this development to the style used in the rehabilitation program, which the latest adaptation of physiology in soft tissue working on the wrist joint, as it responded largely through improvements made in the levels of range of motion. That this technique helps to develop the ability of muscle as well as the speed of movement at higher rates (Ruby et al., 1988).

The adaptive physiological happening in aggregates muscle force will reduce the likelihood of injury, because the injury means the occurrence of movement is physiological and that otherwise the principle of adaptation. That evolution is the result of the quality of the exercises used in the rehabilitation program, which has worked to create the neuromuscular system through the involvement of a number of large motor units at a rate of a quick response to overcome the muscle work assigned to it (Kirkendall \& Garrett, 1998; LaStayo et al., 2003).

The athlete can through stretch exercises that increases the speed of motor units and muscle strength in the joint duty motor, as well as in the development of voluntary activity of the muscles of muscle fibre recruitment during the rapid contraction (Moeslund \& Granum, 2001).

\section{CONCLUSIONS}

1. A program of kinesiology positive effect in rehabilitation of the wrist joint speed up the healing process.

2. To the smart programs used in kinetic analysis of an active role in the calculation of the amount of force and variables of subsidiaries kinesiology.

3. Significant differences in the results of the pre-test and post-test for variable range of motion through improved movement of the wrist joint.

4. Significant differences in the results of the pre-test and post-test for variable grip force, time and force endurance.

5. The use of science kinesiology in rehabilitation programs with a significant impact in increasing muscular balance and stability hinge.

\section{REFERENCES}

Ben Aabdallah, I., Bouteraa, Y., \& Rekik, C. (2016). Design of smart robot for wrist rehabilitation. International Journal on Smart Sensing \& Intelligent Systems, 9(2). https://doi.org/10.21307/ijssis2017-906

Floyd, R.T. (2004). Thompson CW. Manual of structural kinesiology: McGraw-Hill New York.

Hambangmoe-ro, I., \& Sujeong-gu, S-s. (2015). An analysis of the motion pattern of a bedside exercise rehabilitation program using a 3-axis accelerometer.

Hill, J., Basic Biomechanics, S. (2012). Library of Congress Cataloging-in-Publication Data, 2, 525. 
Kirkendall, D. T., \& Garrett, W. E. (1998). The effects of aging and training on skeletal muscle. The American journal of sports medicine, 26(4), 598-602. https://doi.org/10.1177/03635465980260042401

LaStayo, P. C., Ewy, G. A., Pierotti, D. D., Johns, R. K., \& Lindstedt, S. (2003). The positive effects of negative work: increased muscle strength and decreased fall risk in a frail elderly population. The Journals of Gerontology Series A: Biological Sciences and Medical Sciences, 58(5), M419-M424. https://doi.org/10.1093/gerona/58.5.M419

McLean, S. G., Fellin, R. E., Suedekum, N., Calabrese, G., Passerallo, A., \& Joy, S. (2007). Impact of fatigue on gender-based high-risk landing strategies. Medicine and science in sports and exercise, 39(3), 502-514. https://doi.org/10.1249/mss.0b013e3180d47f0

Moeslund, T. B., \& Granum, E. (2001). A survey of computer vision-based human motion capture. Computer vision and image understanding, 81(3), 231-268. https://doi.org/10.1006/cviu.2000.0897

Ruby, L., Conney, W., An K-N, Linscheid, R., Chao, E. (1988). Relative motion of selected carpal bones: a kinematic analysis of the normal wrist. The Journal of hand surgery, 13(1), 1-10. https://doi.org/10.1016/0363-5023(88)90189-X 